\title{
Long-Term Oral Corticosteroid-Therapy: Description of the Practice of Adjuvant Measures by Dakar Medical Specialists
}

\author{
M. Dieng1*, B. Djiba1, M. Sow ${ }^{1}$, B. S. Kane1, J. T. Ahouandogbo', M. Ba1, M. A. Ndour ${ }^{1}$, B. C. Fall' ${ }^{2}$,

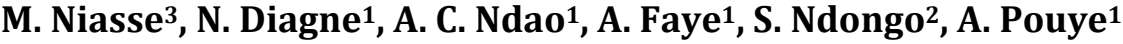 \\ ${ }^{1}$ Department of Internal Medicine, Aristide Le Dantec Hospital, Dakar-Etoile, Senegal \\ ${ }^{2}$ Department of Internal Medicine, Dalal Jam Hospital, Dakar, Senegal \\ ${ }^{3}$ Department of Rheumatology, Aristide Le Dantec Hospital, Dakar-Etoile, Senegal \\ Email: *docmdieng@gmail.com
}

How to cite this paper: Dieng, M., Djiba, B., Sow, M., Kane, B.S., Ahouandogbo, J.T., Ba, M., Ndour, M.A., Fall, B.C., Niasse, M., Diagne, N., Ndao, A.C., Faye, A., Ndongo, S. and Pouye, A. (2020) Long-Term Oral Corticosteroid-Therapy: Description of the Practice of Adjuvant Measures by Dakar Medical Specialists. Open Journal of Rheumatology and Autoimmune Diseases, 10 , 70-78.

https://doi.org/10.4236/ojra.2020.102009

Received: April 19, 2020

Accepted: May 11, 2020

Published: May 14, 2020

Copyright $\odot 2020$ by author(s) and Scientific Research Publishing Inc. This work is licensed under the Creative Commons Attribution International License (CC BY 4.0).

http://creativecommons.org/licenses/by/4.0/

\begin{abstract}
Introduction: The extended administration of corticoids by oral way for a length of more than 3 months defines the long-term-corticosteroid-therapy. This one, used in numerous indications, displays most often at the risk of undesirable effects linked sometimes to the habits of prescription of the doctors. Patients and Methods: In order to study the prescription modalities of this treatment, we conducted a cross-sectional, multicentric and descriptive study from June 1st, 2017 to August 1st, 2017, over a period of 2 months. It involved a questionnaire given to medical specialists of all medical specialties and practicing in the University Hospital of Dakar. Results: 170 doctors were interviewed. Dermatologists and internists were mostly found $19.4 \%$ and $18.8 \%$ or $33 \%$ and $34 \%$ doctors. Systemic autoimmune diseases alone accounted for $48 \%$ of prescription reasons. Prednisone was prescribed in $88 \%$ of cases. The immunosuppressive dose of $1 \mathrm{mg} / \mathrm{kg}$ was most often prescribed. Practitioners very heterogeneously prescribe most adjuvant measures to prolonged systemic corticosteroid therapy. Thus, the recommendation of a low-sodium diet (38\% of physicians), and the systematic prescriptions of proton pump inhibitors (44.7\% of physicians) and vitamin-calcium supplementation were frequently performed by physicians ( $34 \%$ of physicians). While the low carbohydrate diet was advocated by less than a quarter of doctors and the prevention of pneumocystosis and osteoporosis were rare (respectively 61\% and 52\% of prescribers did not). Conclusion: The global analysis of the habits of our medical specialists concerning the use of long-term glucocorticoids reflected a diversity of indications, heterogeneity of practices, with certain habits not in accordance with the usual recommendations.
\end{abstract}


Keywords

Corticosteroid, Long-Term Oral Corticosteroid, Systemic Disease, Adjuvant Measures

\section{Introduction}

The term corticosteroids correspond to the natural hormones secreted by adrenal cortex as well as their synthetic derivatives mainly used for their anti-inflammatory properties [1].

Extended corticosteroid therapy is defined by the use of steroids for a period of at least three months. They occupy a major place in the anti-inflammatory therapy and show a remarkable effectiveness in the treatment of chronic pathologies.

It is estimated that $0.2 \%$ to $0.5 \%$ of the general population receives prolonged systemic corticosteroids [2] [3]. In the United Kingdom, about $0.85 \%$ of the adult British population and up to $2.5 \%$ of the population over 70 years of age take long-term corticosteroid therapy [2]. In the United States, new oral corticosteroids are being introduced in ten million people every year [4] [5]. In France, more than two million prescriptions a year prescribe glucocorticoids and several hundred thousand people are treated each year with corticosteroids [5]. We have no data on the use of glucocorticoids in sub-Saharan Africa.

Since their discovery, they have been the subject of many works to streamline their indications. The first years of their use were marked by the probably excessive development of delayed products prescribed at empirical doses. This attitude has helped amplify the much-dreaded side effects [6]. Their prescription for extended periods exposes the patient to many side effects that the therapist will have to take into account in managing the treatment. The importance and consequences of these side effects depend on a large number of parameters (dosage, duration of treatment, ...). Today, after seven decades of use, several reasons explain the need to take stock of the use of glucocorticoids:

- Increasing the frequency of prescription of glucocorticoids: the prevalence of use has increased by more than $30 \%$ over the last 20 years [7].

- Heterogeneity of corticotherapy practices from one practitioner to another concerning therapeutic strategies, adjuvant measures, pre-treatment assessments, stopping procedures.

- The doctor's enthusiasm, the reluctance of the patient: The proven efficacy of glucocorticoids contrasts with a tolerance often mediocre and a reluctance of the patient, even considering that corticosteroids are more dangerous than anti-vitamin $\mathrm{K}$ or non-anti-inflammatory drugs steroidal; this probably impacts the level of adherence to corticosteroids [8] [9] [10].

- The need to consider some undesirable effects, those feared but exceptional (or nonexistent?), Others unknown despite their frequency and severity. 
In an attempt to provide answers to some of these questions, we conducted a cross-sectional, multicenter and descriptive study on the use of adjunctive measures to prolonged oral corticosteroids by specialist physicians practicing in Dakar University Hospital Centers and Public Hospitals.

\section{Patients and Methods}

It was a cross-sectional, multicentric, descriptive study from June the $1^{\text {st }} 2017$ to August the $1^{\text {st }} 2017$, over a study period of 2 months. It involved a questionnaire given to the target practitioners.

All internal hospital practitioners, physicians in specialization, university assistants, associate lecturers, full professors and all other non-academic specialists were included. The target specialties were Internal Medicine, Rheumatology, Nephrology, Dermatology, Pulmonology, Infectious Diseases, Cardiology, Hematology, Hepatogastroenterology and Neurology.

All questionnaires that were not completed or completed and not brought within the specified time frame were not included. All questionnaires with incomplete answers were excluded.

We even made the collection of these data using a sheet that we made. It consisted of three large parts. The first part concerned the identification of practitioners, his/her hospital-grade, his level of specialization if he is an intern or a doctor in specialized training, his medical specialty. The second part concerned the prescription procedure. The last part concerned the frequency of prescription of various measures associated with prolonged systemic corticosteroid therapy (low-carbohydrate diet, low-sodium diet, prevention of pneumocystosis, $\mathrm{D}$ vitamin and calcium supplementation, biphosphonates, proton pump inhibitors, osteodensitometry evaluation at M0 then M6 treatment).

The various questions asked were in the form of single choice questions. Completed and submitted questionnaires were analyzed by sphinx software.

\section{Results}

Of the 230 questionnaires distributed, 170 were completed and re-addressed, representing a response rate of $73 \%$. The main characteristics of responder practitioners as well as the main indications for glucocorticoids are reported in Figure 1 and Figure 2. These practitioners were mainly internists and dermatologists and practiced mainly in hospitals as hospital practitioners. They used to prescribe prolonged oral corticosteroids, at an immunosuppressive dose, preferably prednisone.

Table 1 describes the frequency of prescription of various adjuvant measures to corticosteroid therapy. Among the dietary measures, none seemed to be unanimous among doctors. Low sodium diet was frequently prescribed in $38 \%$ of physicians, as well as the systematic vitamin-calcium and potassium supplementation. Respectively $61 \%$ and $52 \%$ of doctors never achieve prevention of pneumocystosis and osteoporosis. 


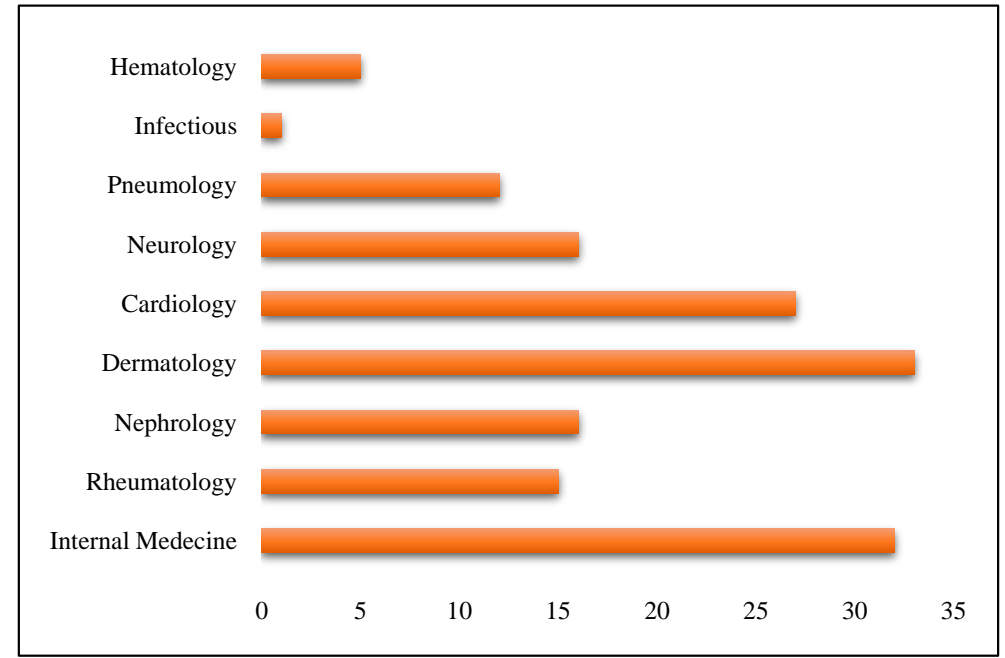

Figure 1. Specialties of the doctors.

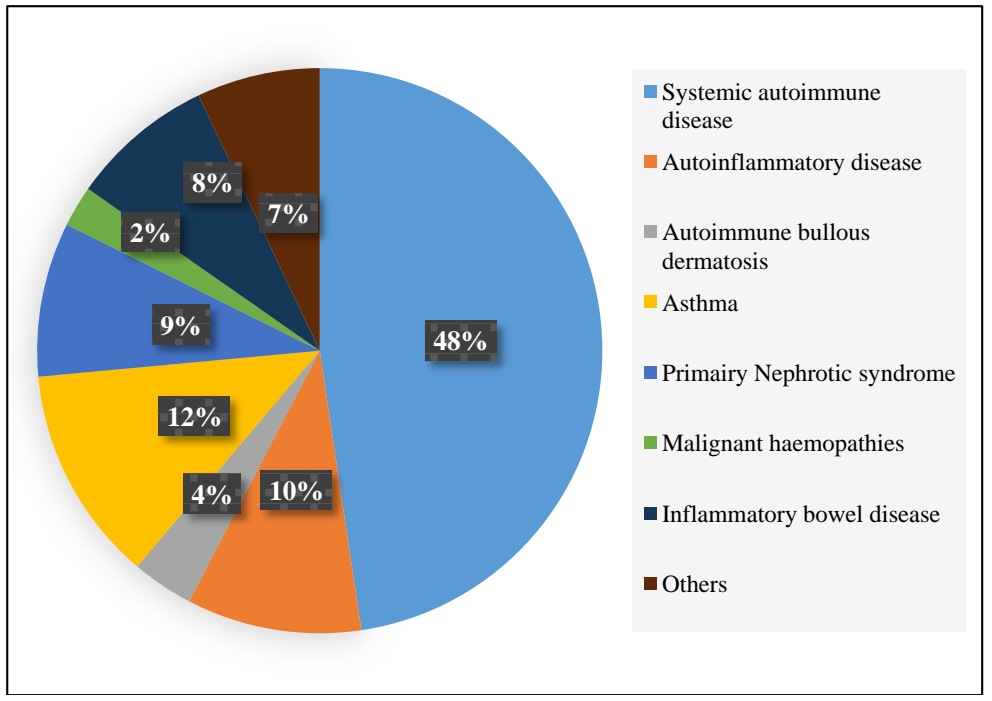

Figure 2. Main indications of extended oral corticosteroid therapy.

Table 1. Description of the frequency of prescription of various adjuvant measures to corticosteroid therapy.

\begin{tabular}{cccccc}
\hline Frequency & $\begin{array}{c}\text { Hyposode } \\
\text { diet }\end{array}$ & $\begin{array}{c}\text { Carbohydrat } \\
\text { diet }\end{array}$ & $\begin{array}{c}\text { Vit D-Calcium } \\
\text { Supplementation }\end{array}$ & $\begin{array}{c}\text { Potassium } \\
\text { Supplementation }\end{array}$ & Osteodensitometry \\
\hline Never & $6 \%$ & $16 \%$ & $8 \%$ & $10 \%$ & $65 \%$ \\
Sometimes & $24 \%$ & $35 \%$ & $21 \%$ & $28 \%$ & $23 \%$ \\
Frequently & $38 \%$ & $22 \%$ & $33 \%$ & $28 \%$ & $6 \%$ \\
Always & $32 \%$ & $27 \%$ & $38 \%$ & $34 \%$ & $6 \%$ \\
\hline
\end{tabular}

\section{Discussion}

This study, carried out with the help of 170 Senegalese medical specialists, shows that most adjuvant measures for prolonged systemic corticosteroids are prescribed in a very heterogeneous manner by practitioners. Thus, the advocacy of a 
low-sodium diet and the systematic prescriptions of proton pump inhibitor, vitamin-calcium supplementation were frequently performed by doctors. While the low carbohydrate diet was advocated by less than a quarter of doctors and the prevention of pneumocystosis and osteoporosis were rare.

There are no recommendations for dietary measures to be prescribed in combination with prolonged systemic corticosteroids. Low sodium diet is frequently recommended. The reason for this prescription remains obscure. Some people have the idea that a diet low in sodium could prevent corticosteroid lipodystrophy (the so-called "cushingoid syndrome"). It has been shown that sodium intake is not associated with the risk of developing this complication of treatment [11]. Others associate sodium intake and risk of developing or increasing corticoinduced hypertension. However, the physiopathological mechanisms responsible for this iatrogenic hypertension are imperfectly known and several studies have shown that corticosteroid-induced hypertension was probably not related to this mineralocorticoid activity [12]-[18]. It has been suggested that the mechanisms of corticosteroid-induced hypertension may involve an increase in peripheral vascular resistance and an increase in cardiac contractility [19]. These arguments therefore call into question, at least partially, the interest of a low-sodium diet, a very restrictive regime for the patient [20]. Glucocorticoids are frequently associated with insulin resistance and diabetes [21] [22] [23]. An American study estimated the relative risk of introducing a hypoglycemic drug after initiation of steroids at 2.23, with a clear dose effect. A British epidemiological study indicates an increased risk of diabetes (odds ratio [OR]: 1.36) in patients exposed to general corticosteroid therapy.

Diabetic patients receiving corticosteroid therapy also have higher glycated hemoglobin levels than diabetic patients who do not receive corticosteroids. The relationship between this elevation and the occurrence of cardiovascular events is however uncertain [20].

It is customary to recommend that patients exposed to glucocorticoids adapt their diet to a diabetic diet. The impact of this recommendation in terms of onset of diabetes or cardiovascular complications is unknown. Regarding corticosteroid therapy in diabetics, it is likely that the limitation of weight gain and regular physical exercise are also beneficial to the glycemic balance under corticosteroids. The threshold of drug intervention is not the subject of any consensus. The interest of introducing a hypoglycemic treatment to restore the only vestigial glycemic balance is not obvious. There is a real risk of hypoglycaemia, especially with decreasing corticosteroid therapy. The control of the inflammatory syndrome by the steroids sometimes allows the return to satisfactory glycemic equilibrium! Some authors apply the treatment modalities for type 2 diabetes and rely heavily on oral hypoglycemic agents as long as post-prandial or afternoon blood glucose levels do not exceed $3 \mathrm{~g} / \mathrm{L}$ [24].

The co-prescription of a proton pump inhibitor was systematically performed in $44.7 \%$ of the physicians we interviewed. This was not justified. Indeed, the ulcerogenic risk of corticosteroids is widely debated. The High Authority of Health 
on the prescription of proton pump inhibitors, recommends: not to perform primary prevention in patients receiving corticosteroids unless they receive at the same time non-steroidal anti-inflammatory drugs. There is no study on duration of treatment or risk [25] [26].

Vitamin-calcium supplementation was routinely prescribed by $38 \%$ (65 cases) of physicians in addition to corticosteroid therapy.

The administration of calcium and vitamin $\mathrm{D}$ on pathophysiological bases is largely performed during the prescription of GC, but its benefit is not established. Indeed, the observation of placebo groups of major therapeutic trials, in which patients receive physiological doses of calcium and vitamin $\mathrm{D}$, shows that bone loss and fractures are not prevented in these groups. The calcium intake recommended by the National Health and Nutrition Program (PNSS) is 800 1200 grams. To cover these needs, it is necessary to consume four dairy products per day (yogurts, fresh cheeses, fermented milks, cheeses, milk ...). In addition, the association of increased incidence of cardiovascular events with calcium supplementation in older women has been suggested. It has been reported mainly in subjects whose spontaneous dietary calcium intake was already sufficient, but it is not confirmed [27] [28] [29]. Offsetting dietary calcium deficiencies reduces the added risk factors for bone loss. Inputs should be evaluated by a food survey. Systematic prescription of calcium supplementation is not recommended (Grade A).

As for the prescription of vitamin $\mathrm{D}$, it is not recommended systematically. In the event of a situation of potential bone fragility linked to the underlying inflammatory disease and the use of glucocorticoids, the determination of serum vitamin D (25 OH vitamin D) is indicated (Grade A). In case of vitamin D insufficiency or deficiency, it is recommended to prescribe an "attack" treatment which will make it possible to obtain a $25-(\mathrm{OH})$-vitamin D level above the target value of $30 \mathrm{ng} / \mathrm{mL}$ (Grade A). The maintenance treatment dosage is 800 to 1200 IU/day (or equivalent doses of 100,000 IU every 2 to 3 months) [20].

Similarly, potassium supplementation is poorly justified; screening for hypokalemia after one month and three months of treatment is recommended [20].

Our doctors poorly realize the prevention of pneumocystosis and osteoporosis, which is so important in tropical environments and in some people at risk of osteoporosis. However, corticosteroid therapy has been identified as a risk factor for the development of pneumocystosis in patients transplanted or treated for cancer or systemic disease [30] [31] [32]. The highest risk is particularly related to granulomatosis with polyangitis. However, habits differ from one team to another. No consensus is retained on the action threshold. Some teams rely on the determination of CD4 T cell count to make their decision [33]; other teams provide prophylaxis to any patient receiving at least $20 \mathrm{mg}$ daily corticosteroid therapy for a period of at least one month, in the case of a patient with another immunosuppressive factor added to that resulting from corticosteroid therapy (immunosuppressive treatment for example) [34]. In addition, for the preven- 
tion of osteoporosis, a bone mineral density (BMD) measurement is recommended for all patients starting oral corticosteroid therapy or already receiving oral corticosteroid therapy for more than 3 months (if the initial assessment not done), regardless of dose (grade $\mathrm{C}$ ). The treatment with anti-osteoporosis, depends or not on the existence of indications.

Our work has two main limitations. First, concerning practitioners, a non-response bias must be mentioned. It is possible that doctors who did not answer our questionnaire have very different medical practices from those who did. Nevertheless, considering the fact that the number of nonresponse is very little, we think that these results reflect the general practice of the Senegalese doctors. Despite these limitations, this study has shown that while some measures seemed to win the support of the majority, the other adjuvant measures were prescribed in a disparate way. Due to the large number of patients receiving extended systemic corticosteroids that we are taking care of, and in the absence of prospective studies of most of the measures that should be associated with this treatment, consensus recommendations would be welcome.

\section{Conflicts of Interest}

The authors declare no conflicts of interest regarding the publication of this paper.

\section{References}

[1] Le Jeune, C. (2012) Pharmacologie des glucocorticoïdes. La Presse Médicale, 41, 370-377. https://doi.org/10.1016/j.lpm.2012.01.007

[2] Van Staa, T.P., Leufkens, H.G., Abenhaim, L., Begaud, B., Zhang, B. and Cooper, C. (2000) Use of Oral Corticosteroids in the United Kingdom. QJM: An International Journal of Medicine, 93, 105-111. https://doi.org/10.1093/qjmed/93.2.105

[3] Walsh, L.J., Wong, C.A., Pringle, M. and Tattersfield, A.E. (1996) Use of Oral Corticosteroids in the Community and the Prevention of Secondary Osteoporosis: A Cross Sectional Study. British Medical Journal, 313, 344-346. https://doi.org/10.1136/bmj.313.7053.344

[4] Fardet, L., Kassar, A., Cabane, J. and Flahault, A. (2007) Corticosteroid-Induced Adverse Events in Adults: Frequency, Screening and Prevention. Drug Safety, 30, 861-881. https://doi.org/10.2165/00002018-200730100-00005

[5] Fardet, L., Petersen, I. and Nazareth, I. (2011) Description des prescriptions de corticothérapies orales en population générale. La Revue de médecine interne, 32, 594-599. https://doi.org/10.1016/j.revmed.2011.02.022

[6] Godeau, P. (1990) Corticothérapie. La Revue du praticien, 40, 509-510.

[7] Fardet, L., Petersen, I. and Nazareth, I. (2011) Prevalence of Long-Term Oral Glucocorticoid Prescriptions in the UK over the Past 20 Years. Rheumatology (Oxford), 50, 1982-1990. https://doi.org/10.1093/rheumatology/ker017

[8] Cullen, G., Kelly, E. and Murray, F.E. (2006) Patients' Knowledge of Adverse Reactions to Current Medications. British Journal of Clinical Pharmacology, 62, 232-236. https://doi.org/10.1111/j.1365-2125.2006.02642.x

[9] Morisson, E., Crosbie, D. and Capell, H.A. (2003) Attitude of Rheumatoid Arthritis 
Patients to Treatment with Oral Corticosteroids. Rheumatology (Oxford), 42, 1247-1250. https://doi.org/10.1093/rheumatology/keg355

[10] Zerah, L., Arena, C., Morin, A.S., Blanchon, T., Cabane, J. and Fardet, L. (2012) Patients' Beliefs about Long-Term Glucocorticoid Therapy and Their Association to Treatment Adherence. La Revue de Médecine Interne, 33, 300-304. https://doi.org/10.1016/j.revmed.2012.02.001

[11] Fardet, L., Cabane, J., Lebbé, C., Morel, P. and Flahault, A. (2007) Incidence and Risk Factors for Corticosteroid-Induced Lipodystrophy: A Prospective Study. Journal of the American Academy of Dermatology, 57, 604-609.

https://doi.org/10.1016/j.jaad.2007.04.018

[12] Kelly, J.J., Mangos, G., Williamson, P.M. and Whitworth, J.A. (1998) Cortisol and Hypertension. Clinical and Experimental Pharmacology and Physiology, 25, S51-S56. https://doi.org/10.1111/j.1440-1681.1998.tb02301.x

[13] Whitworth, J.A., Schyvens, C.G., Zhang, Y., Mangos, G.J. and Kelly, J.J. (2001) Glucocorticoid-Induced Hypertension: From Mouse to Man. Clinical and Experimental Pharmacology and Physiology, 28, 993-996. https://doi.org/10.1046/j.1440-1681.2001.03584.x

[14] Whitworth, J.A., Gordon, D., Andrews, J. and Scoggins, B.A. (1989) The Hypertensive Effect of Synthetic Glucocorticoids in Man: Role of Sodium and Volume. Journal of Hypertension, 7, 537-549. https://doi.org/10.1097/00004872-198907000-00005

[15] Truhan, A.P. and Ahmed, A.R. (1989) Corticosteroids: A Review with Emphasis on Complications of Prolonged Systemic Therapy. Annals of Allergy, 62, 375-391.

[16] Whitworth, J.A. and Kelly, J.J. (1995) Evidence that High Dose Cortisol-Induced $\mathrm{Na}+$ Retention in Man Is Not Mediated by the Mineralocorticoid Receptor. Journal of Endocrinological Investigation, 18, 586-591. https://doi.org/10.1007/BF03349774

[17] Montrella-Waybill, M., Clore, J.N., Schoolwerth, A.C. and Watlington, C.O. (1991) Evidence that High Dose Cortisol-Induced $\mathrm{Na}+$ Retention in Man Is Not Mediated by the Mineralocorticoid Receptor. The Journal of Clinical Endocrinology \& Metabolism, 72, 1060-1066. https://doi.org/10.1210/jcem-72-5-1060

[18] Williamson, P.M., Kelly, J.J. and Whitworth, J.A. (1996) Dose-Response Relationships and Mineralocorticoid Activity in Cortisol-Induced Hypertension in Humans. Journal of Hypertension. Supplement, 14, S37-S41.

[19] Fardet, L., Hanslik, T., Blanchon, T., Perdoncini-Roux, A., Kettaneh, A., Tiev, K.P., et al. (2008) Long-Term Systemic Corticosteroid-Therapy Associated Measures: Description of the French Internal Medicine Physicians' Practices. La Revue de Médecine Interne, 29, 975-980. https://doi.org/10.1016/j.revmed.2008.04.001

[20] Ong, S.L., Zhang, Y. and Whitworth, J.A. (2008) Reactive Oxygen Species and Glucocorticoid-Induced Hypertension. Clinical and Experimental Pharmacology and Physiology, 35, 477-482. https://doi.org/10.1111/j.1440-1681.2008.04900.x

[21] Van Everdingen, A.A., Jacobs, J.W., Siewertsz Van Reesema, D.R. and Bijlsma, J.W. (2002) Low-Dose Prednisone Therapy for Patients with Early Active Rheumatoid Arthritis: Clinical Efficacy, Disease-Modifying Properties, and Side Effects: A Randomized, Double-Blind, Placebo-Controlled Clinical Trial. Archives of Internal Medicine, 136, 1-12. https://doi.org/10.7326/0003-4819-136-1-200201010-00006

[22] Conn, H.O. and Poynard, T. (1994) Corticosteroids and Peptic Ulcer: Meta-Analysis of Adverse Events during Steroid Therapy. Journal of Internal Medicine, 236, 619-632. https://doi.org/10.1111/j.1365-2796.1994.tb00855.x

[23] Gurwitz, J.H., Bohn, R.L., Glynn, R.J., Monane, M., Mogun, H. and Avorn, J. (1994) 
Glucocorticoids and the Risk for Initiation of Hypoglycemic Therapy. Archives of Internal Medicine, 154, 97-101.

https://doi.org/10.1001/archinte.1994.00420010131015

[24] Reynolds, R.M., Labad, J., Sears, A.V., Williamson, R.M., Strachan, M.W., Deary, I.J., et al. (2012) Glucocorticoid Treatment and Impaired Mood, Memory and Metabolism in People with Diabetes: The Edinburgh Type 2 Diabetes Study. European Journal of Endocrinology, 166, 861-868.

https://doi.org/10.1530/EJE-12-0041

[25] Messer, J., Reitman, D., Sacks, H.S., Smith, H. and Chalmers, T.C. (1983) Association of Adrenocorticosteroid Therapy and Peptic-Ulcer Disease. The New England Journal of Medicine, 309, 21-24. https://doi.org/10.1056/NEJM198307073090105

[26] Luo, J.C., Chang, F.Y., Lin, H.Y., Lu, R.H., Lu, C.L., Chen, C.Y., et al. (2002) The Potential Risk Factors Leading to Peptic Ulcer Formation in Autoimmune Disease Patients Receiving Corticosteroid Treatment. Alimentary Pharmacology \& Therapeutics, 16, 1241-1248. https://doi.org/10.1046/j.1365-2036.2002.01279.x

[27] El-Khoury, F., Cassou, B., Charles, M.A., et al. (2013) The Effect of Fall Prevention Exercise Programmes on Fall Induced Injuries in Community Dwelling Older Adults: Systematic Review and Meta-Analysis of Randomised Controlled Trials. British Medical Journal, 347, f6234.

[28] Bolland, M.J., Barber, P.A., Doughty, R.N., et al. (2008) Vascular Events in Healthy Older Women Receiving Calcium Supplementation: Randomised Controlled Trial. British Medical Journal, 336, 262-266. https://doi.org/10.1136/bmj.39440.525752.BE

[29] Benhamou, C.L., Souberbielle, J.C., Cortet, B., et al. (2011) Pour le Groupe de Rechercheet d'information sur les Ostéoporoses (GRIO). La vitamine D chez l'adulte: Recommandations du GRIO. La Presse Médicale, 40, 673-682. https://doi.org/10.1016/j.lpm.2011.04.001

[30] Sepkowitz, K.A., Brown, A.E., Telzak, E.E., Gottlieb, S. and Armstrong, D. (1992) Pneumocystis carinii Pneumonia among Patients without Aids at a Cancer Hospital. The Journal of the American Medical Association, 267, 832-837. https://doi.org/10.1001/jama.1992.03480060078034

[31] Sepkowitz, K.A. (1993) Pneumocystis carinii Pneumonia in Patients without Aids. Clinical Infectious Diseases, 17, S416-S422. https://doi.org/10.1093/clinids/17.Supplement 2.S416

[32] Sepkowitz, K.A. (2002) Opportunistic Infections in Patients with and Patients without Acquired Immunodeficiency Syndrome. Clinical Infectious Diseases, 34, 1098-1107. https://doi.org/10.1086/339548

[33] Gluck, T., Geerdes-Fenge, H.F., Straub, R.H., Raffenberg, M., Lang, B., Lode, H., et al. (2000) Pneumocystis carinii Pneumonia as a Complication of Immunosuppressive Therapy. Infection, 28, 227-230. https://doi.org/10.1007/s150100070041

[34] Beck, J.M. and Harmsen, A.G. (1998) Lymphocytes in Host Defense against Pneumocystis carinii. Seminars in Respiratory Infections, 13, 330-338. 